\title{
THE ROYAL SOCIETY OF ARTS
}

\section{BICENTENARY CELEBRATIONS}

$\mathrm{T}$ HE first official meeting of the Society of Arts took place on March 22, 1754, and the exact anniversary two hundred years later fell on a Monday, so that the first day of a week of celebrations was also in some respects the most important.

On March 22, 1954, three events were arranged, two of them of more or less public a character and the third private. The celebrations opened with a service at the Church of St. Martin-in-the-Fields, when the Society met probably for the first time in its history in such a building and for such a purpose. But the service was unusual not only because of its uniqueness in the Society's history, but also in its own character, and particularly from the musical point of view. As the organ was under repair, the singing was accompanied by an orchestra which, together with the choir, was provided by members of staff and students of Trinity College of Music, under the direction of the principal, Dr. Greenhouse Allt, who is a Fellow of the Society. One item of music was of special interest, the Trio Sonata No. 2 of Thomas Augustine Arne, who was one of the early members of the Society. The sonata has only recently been published, and this was probably its first public performance for 150 years. The execution of the music was throughout of a very high quality and the Te Deum (Vaughan Williams in G) in particular formed a most impressive climax to the service. The sermon was preached by the Bishop of Peterborough, who reviewed from the spiritual point of view the bewildering scientific and material progress of the past two hundred years and closed with the words of Francis Bacon : "The final end of all knowledge is the glory of the Creator and the relief of man's estate".

In the afternoon the chairman of Council, the Earl of Radnor, who is the lineal descendant of the Society's first president, Viscount Folkestone, received congratulatory addresses from representatives, in most cases the presidents, of nearly sixty other organizations, many of which, and in particular several from overseas, owe their origin in some degree to the activities of the Royal Society of Arts. It was a colourful scene as the representatives, many of them in academic robes, advanced singly, and with a quiet dignity befitting the eighteenth-century room in which the ceremony took place, to present the tribute of their organization. The ceremony concluded with a short address from Lord Samuel, retrospective but never nostalgic, in which he called upon the members of the Society of the present day to exercise the same faith and hope as moved the Society's founders and to sustain their good work for the sake of the generations that are still to come.

The day's events concluded in a more private manner, when the members of the Society's Council and their ladies dined informally at Tallow Chandlers Hall, and in this way commemorated the fact that the Society's first meeting took place in somewhat similar surroundings at Rawthmell's Coffee House. After dinner, students of the Royal Academy of Dramatic Art presinted a scene from "She Stoops to Conquer" : Goldsmith was not only one of the early members of the Society, but was also actually an applicant in 1760 for its secretaryship.

On the afternoons of Tuesday, Wednesday and Thursday a series of three masterly addresses was delivered by Prof. N. B. L. Pevsner, Sir Ben Lockspeiser and Sir Geoffrey Heyworth, on the progress of "Arts", "Manufactures" and "Commerce" respectively during the past two hundred years, this pattern of themes being based on the Society's full title, "The Royal Society for the Encouragement of Arts, Manufactures and Commerce". Prof. Pevsner concentrated mostly on the history of industrial design during this period and, while recounting its promotion by the Society at various periods during the two hundred years, particularly emphasized the influence which it exerted in the years succeeding the Great Exhibition by its forthright attitude to contemporary design. Sir Ben Lockspeiser, in a survey of science in its application to industry during the past two hundred years, looked back, as it were, to Prof. Pevsner's lecture and emphasized the need for improved technology to go hand-in-hand with imaginative design, and looked forward to Sir Geoffrey Heyworth's subject, hinting at the contribution which science can now make to accountancy and many other clerical operations. In the last of the three lectures Sir Geoffrey Heyworth, in dealing with the subject of "Commerce", concentrated his attention upon the history of education for commerce, to which the Society itself has made and continues to make so important a contribution, and, in surveying the past two hundred years, he showed what had been achieved, first by the ordinary day school, then by institutions mainly operating in the evenings for specific training for commerce, and finally, through the acceptance of commercial subjects as appropriate to a university.

The fitting conclusion of the week's celebrations was a banquet, the first official dinner of the Society for ninety-two years, which was held at the neighbouring Savoy Hotel on Friday evening and at which T.R.H. the Duke and Duchess of Gloucester were present. Lord Woolton, a Fellow of the Society, represented Her Majesty's Government, and the Lord Mayor of London was there to represent civic government. In proposing the toast of the Society the Duke of Gloucester emphasized three aspects of its character, which he termed its disinterestedness, its humanity and its ability to combine the virtues of youth and age. Lord Radnor replied, and responses to the toast of the guests, which was proposed by Sir Ernest Goodale, were made by Dr. E. D. Adrian, speaking for the men guests and science, and Dame Ninette de Valois, representing the ladies and the arts. Dr. Adrian emphasized the influence which the Society, as a body interested equally in the arts and the sciences, could exercise towards securing that the discoveries of science were applied in a way that was beneficial and not harmful to the community, while Dame Ninette appealed to it for its support for the youngest of the arts.

Fortunately this festive week doэs not entirely complete the Society's celebrations of its bicentenary, as it is able to look forward to a reception which is being arranged to be held at St. James's Palace later in the year when its president, H.R.H. the Duke of Edinburgh, whose absence at this time was so keenly felt, can hope to be present.

In addition to these special events, the Society is commemorating its bicentenary by several actions of varying kinds. Its bicentenary competition, in which 
ideas of life in A.D. 2000 were invited, has already been announced. The Council has also decided to institute a medal, to be known as the Bicentenary Medal, which will be awarded annually to a patron of industrial design, and a new history of the Society prepared by Mr. Derek Hudson and the Secretary was published on the day of the bicentenary. Also, a beautiful badge of office for the Chairman of Council designed by Prof. R. Y. Goodden has been presented to the Society by a former chairman of Council, Mr. J. A. Milne, and the Chairman was invested with this for the first time on March 17 in readiness for the forthcoming bicentenary functions.

KENNETH W. LUCKHURST

\title{
SUN NAVIGATION BY ANIMALS
}

\author{
By Dr. H. KALMUS \\ Galton Laboratory, University College, London
}

$I^{\mathrm{T}}$ $T$ has for a long time been suspected that sun navigation must play an important part in the movements of homing and migrating animals; but until recently the evidence for its existence was not convincing, often contradictory, and the way in which it could work remained mysterious. However, experiments published during the past two years on honey bees ${ }^{1}$, amphipods (Talitrus saltator) ${ }^{2}$ and birds ${ }^{3,4}$ have not only demonstrated the existence of sun navigation beyond doubt, but have also shown that it is based in all three groups on a combination of two widely found faculties, namely, the perception and memory of angles and a change according to a twenty-four-hour rhythm of a reference system operating in the brain of the animal. As the orientational behaviour of honey bees is better known than that of the other species, it will be discussed first.

Worker bees, in a dark hive-like container, have been shown to perceive and to remember the angle between two straight parts of a learned track with great facility ${ }^{5}$, and it has long been established that in the outside world they make use of their sense of direction when flying between their hive and a feeding place ${ }^{6}$.

A combination of indoor and outdoor orientation is the basis of the bees' communication of direction : a forager by dancing on a vertical comb in the dark indicates, by the angle and direction of deviation from the vertical, the angle and direction of a rich source of food from the direction of the sun?.

It was believed for a long time, and on some evidence, that honey bees, once they have learned the angle between the sun and a source of food, will retain this angle unchanged in their memory and will accordingly, like certain ants ${ }^{8}$, strike out in a wrong direction, when they have been forced by the experimenter to remain inside the hive, the deviation depending on the length of their captivity. Lately, however, v. Frisch ${ }^{\mathbf{1}}$ has demonstrated that bees "when orientating with the aid of the sun, take the hour of the day into account". During several fine days $h e$ fed bees at an anise-scented syrup dish $200 \mathrm{~m}$. west from their observation hive. The colony was then removed to a neighbourhood which was quite unfamiliar to the bees, and four identical syrup dishes scented with aniseed were laid $200 \mathrm{~m}$. to the north, the south, the west and the east from the hive. Within three hours, twenty out of twenty-nine bees marked in the first location at the dish on the previous day were caught at the dish west of the hive and seven at the three others; and this hap. pened although the sun had stood in the west when the bees had last fed at the first place, and in the east when they were caught at the second place. Repetitions of this type of experiment using additional precautions against other clues had similar results; but the orientation broke down when the sky was overcast. Additional evidence for a mechanism compensating for the daily movements of the sun is provided by an observation by Lindauer ${ }^{1}$ on an exceptional dancer, who after having found a dish did not leave the hive after $1-2 \mathrm{~min}$. as is the rule, but continued to dance for eighty-seven minutes on a vertical comb. During this time the angle of the axis of the dance with the vertical changed by about $33^{\circ}$, while the movement of the azimuth at the place and time of the observation was $34.5^{\circ}$. Thus there can be little doubt that bees when finding a direction make use of some device which compensates for the daily movements of the sun or perhaps for the changes in the polarization pattern of the sky associated with it which they are known to use in other circumstances. While the possession of this compensating mechanism must be considered to be innate, its setting - like that of an automatic steering device-is effected for any situation, as opportunity arises.

The second example of sun navigation concerns the little crustacean Talitrus saltator, an abundant inhabitant of many sandy beaches in the Mediterranean. These animals when transferred inland will move at a right angle towards the coast-line from which they came, which will normally result in their regaining their habitat. Recently, Pardi and Papi $^{2}$ have shown that to do so they make use of the position of the sun. When the sun was shielded from a few of these crustaceans and was replaced by its mirror image from the opposite direction they moved away from the shore instead of towards it. Like the bees, they could also orientate themselves when in the absence of direct sunlight, provided that some portion of the blue sky, but larger than that necessary for bees, was visible to them, and they could also be deflected by the application of a polarizing sheet. The directions of their movements were independent of the hour of the day, and thus of the changing position of the sun, but dependent on the place of origin of the animals: individuals from a population of the Tyrrhenic coast of Italy, for example, moved westwards, even when brought to the Adriatic coast, while the indigenous animals there moved eastwards. As with the bees, one must assume that the mechanism which compensates for the daily movements of the sun is innate in Talitrus, but unlike bees these crustaceans cannot set the geographical direction in which they move by individual experience ; it seems to be set for each of them once and for ever either by heredity or by early individual experience.

Similar observations were also made on pigeons, starlings and other birds. Kramer ${ }^{3}$, experimenting with starlings, showed that these birds, like Talitrus, 